\title{
CAPÍTULO 29: ELABORAÇÃO DO LICOR DE ROMÃ E CANELA: QUALIDADE FÍSICO-QUÍMICA E MICROBIOLOGICA
}

\section{CHAPTER 29: ELABORATION OF POMEGRANATE AND CINNAMON LIQUOR: PHYSICO-CHEMICAL AND MICROBIOLOGICAL QUALITY}

\author{
, Crisliane Camargo de Sá ${ }^{1}$; Joseane Cristina Pinheiro Pombo ${ }^{2}$; Vanessa Albres Botelho ${ }^{3}$
}

\begin{abstract}
Resumo
O setor de bebidas alcoólicas apresenta relevância econômica no Brasil, com destaque para o crescimento do consumo de licores à base de frutas, o que impulsiona o processamento de frutas pouco exploradas tecnologicamente pela agroindústria, como a romã. O objetivo deste estudo foi elaborar um licor à base de romã e canela e avaliar sua qualidade físico-química e microbiológica. O licor foi avaliado quanto aos parâmetros físico-químicos como $\mathrm{pH}$, acidez, densidade, teor alcoólico, cinzas, extrato seco, sólidos solúveis, açucares (redutores, não redutores e totais) e compostos fenólicos totais; e microbiológicos quanto a presença de Salmonella spp., coliformes, bolores e leveduras. O licor apresentou boa qualidade devido aos valores satisfatórios de $\mathrm{pH}(4,5)$, acidez $(16,67 \mathrm{meq} / \mathrm{L})$, densidade $(1,09 \mathrm{~g} / \mathrm{mL})$, teor alcoólico $(24 \% \mathrm{v} / \mathrm{v})$, cinzas $(0,03 \%)$, extrato seco $(27,94 \mathrm{~g} / \mathrm{L})$, sólidos solúveis totais $\left(30,40{ }^{\circ} \mathrm{Brix}\right)$, açúcares totais $(50,20 \%)$, açúcares redutores $(13,13 \%)$, açucares não redutor $(35,21 \%)$ e compostos fenólicos totais (1041 mg GAE/L). Os resultados da análise microbiológica estão de acordo ao estabelecido pela legislação, o que indica as boas condições sanitárias durante a fabricação da bebida devido a ausência de Salmonella spp., coliformes, bolores e leveduras.
\end{abstract}

Palavras-Chaves: Agroindústria, Bebidas alcoólicas, Processamento de frutas.

\begin{abstract}
The alcoholic beverages sector has economic relevance in Brazil, with emphasis on the growth of consumption of fruit-based liquors, which encourages the fruit processing that are not technologically exploited by the agribusiness, such as pomegranate. The study objective was to develop an pomegranate and cinnamon-based liquor and assess quality physicochemical and microbiological. The liquor was evaluated by physico-chemical parameters, such as $\mathrm{pH}$, acidity, density, alcohol content, ash, dry extract, soluble solids, sugars (reducing, non-reducing and total) and total phenolic compounds; and microbiological by analyses of Salmonella spp., coliforms, molds and yeasts. The liquor showed good quality due to satisfactory $\mathrm{pH}(4.5)$, acidity $(16.67 \mathrm{meq} / \mathrm{L})$, density $(1.09 \mathrm{~g} / \mathrm{mL})$, alcohol content $(24 \% \mathrm{v} / \mathrm{v})$, ash $(0.03 \%)$, dry extract $(27.94 \% \mathrm{~g} / \mathrm{mL})$, total soluble solids $\left(30.40{ }^{\circ} \mathrm{Brix}\right)$, total sugars $(50.20 \%)$, reducing sugars $(13.13 \%)$, non-reducing sugars $(35.21 \%)$ and total phenolic compounds (1041 mg GAE/L). The results of the microbiological analysis are in accordance with the established by the legislation, which indicates the good sanitary conditions during the manufacture of the drink due to the absence of Salmonella spp., Coliforms, molds and yeasts.
\end{abstract}

Keywords: Agribusiness, Alcoholic beverages, Fruit processing.

\section{Introdução}

Devido à sua característica tropical, grande extensão territorial e as mais diversas

\footnotetext{
${ }^{1}$ Graduada em Engenharia de Alimentos, Universidade Federal do Pará, criscamargodesa@gmail.com

${ }^{2}$ Graduada em Engenharia de Alimentos, Universidade Federal do Pará, pombojcp@gmail.com

${ }^{3}$ Prof $^{\mathrm{a}}$ Dr $^{\mathrm{a}}$ do curso de Engenharia de Alimentos, Universidade Federal do Pará, vanessalbres@ufpa.br
} 
condições climáticas, o Brasil é o terceiro maior produtor de frutas do mundo, produzindo uma grande quantidade de frutas ao longo do ano. As frutas são uma alternativa para o desenvolvimento e recuperação da economia local, pois apresentam boa aceitação na população, podendo serem processadas para obter diversos produtos como polpas, geléias, sucos, vinhos, licores, entre outros (PINTO et al., 2017). Dentre estas frutas, destaca-se a Romã (Punica granatum L.), que apesar de ser originaria da Ásia é amplamente encontrada por todo Brasil (SOUSA et al., 2018).

Há um interesse crescente na romã como uma fruta saudável de grande benefício a dieta humana devido a presença de constituintes nutricionais, como vitamina $\mathrm{C}$, fitonutrientes que atuam como antioxidantes, fonte de vitamina B5 (ácido pantotênico) e potássio (ATAÍDE et al., 2018). Dentre os fitonutrientes, destacam-se flavonóides (apigenina e narigenina), antocianinas (cinidina, delfinidina e pelargonidina), taninos (punicalagina), alcalóides, ácido ascórbico, ácidos fenólicos (cafeico, catequínico, clorogênico, orto e paracumárico, elágico, gálico e quínico), ácidos graxos conjugados (ácido púnico) e o ácido ursólico, que isolados ou em combinação, são responsáveis pela atividade antioxidante da fruta (OLIVEIRA et al., 2010; NASCIMENTO JÚNIOR et al., 2016; DANDACHI et al., 2017).

Segundo Almeida et al. (2019), o Brasil se destaca também como um dos maiores produtores de bebidas alcoólicas do mundo, com destaque para o crescimento do consumo de licores de frutas. De acordo com a legislação vigente, licor é a bebida com graduação alcoólica de 15 a $54 \%$ em volume, a $20{ }^{\circ} \mathrm{C}$, com percentual de açúcar superior a 30g/L, elaborado com álcool etílico potável de origem agrícola, destilado alcoólico simples de origem agrícola ou ainda bebidas alcoólicas, adicionada de extrato ou substâncias de origem vegetal ou animal, substâncias aromatizantes, saborizantes, corantes e outros aditivos permitidos em ato administrativo complementar (BRASIL, 2009).

As especiarias são largamente utilizadas como aromatizantes de licores, pois são consideradas agentes de conservação que aumentam o tempo de vida dos alimentos devido possuírem propriedade antioxidantes e ação antimicrobiana, reduzindo ou eliminando bactérias patogênicas, além de agregar valor aos alimentos, permitindo sua diferenciação e diversificação, através de um paladar único (CARRIJO et al., 2012). Uma alternativa é a canela (Cinnamomum zeylanicum), nativa do Sri Lanka (antigo Ceilão) e introduzida no Brasil pelos portugueses (LINGUANOTTO NETO et al., 2016). Trata-se de uma planta aromática que, além de apresentar atividade antifúngica e antibacteriana, possui ainda propriedades antiespasmódica, carminativa, estimulante, tônica, digestiva, adstringente, afrodisíaca, antisséptica, antioxidante, aperiente, hipertensora, sedativa e vasodilatadora 
(GOMES et al., 2018).

Existem basicamente três processos para obtenção do extrato alcoólico: por destilação, por adição de essência e por maceração. A maceração é uma operação unitária, comum em licores naturais produzidos a partir de frutas, que consiste na extração sólido-líquido ou lixiviação, neste processo a matéria-prima fica em contato por um tempo com uma solução hidroalcoólica. O tempo de extração é um fator importante no processamento de licores para garantir a completa extração dos componentes desejáveis e as fontes de álcool potável podem ser o álcool de cereais, vodca, cachaça, conhaque e o uísque. Em seguida, ocorre a filtração para obtenção do extrato alcoólico que contém os elementos essenciais que conferirão cor, sabor e aroma ao produto (TEIXEIRA et al., 2011; TEIXEIRA et al., 2012). De acordo com Oliveira et al. (2016), os segredos da qualidade dos licores de frutas estão na combinação perfeita de seus componentes, especialmente a matéria-prima (álcool), a fruta utilizada e o açúcar, bem como nos processos de preparação (infusão) e maturação, que resultarão em um produto integrado com harmonia entre cor, aroma e sabor.

O processamento de licores é uma tecnologia simples, uma vez que, não exige técnicas complexas ou equipamentos de alta complexidade por parte do produtor, e quando produzido de forma apropriada resulta em bebidas de excelente qualidade, com extensa vida de prateleira e que podem ser comercializadas em temperatura ambiente, evitando assim, a onerosa cadeia do frio (TEIXEIRA et al., 2010; TEIXEIRA et al., 2012). Além de agregar valor ao fruto, estender sua vida pós-colheita e possibilitar o aumento na renda de pequenos agricultores (OLIVEIRA et al., 2015; SOUZA et al., 2019).

O mercado de licores de frutas pode ser facilmente explorado, pelo uso de fontes renováveis (ALMEIDA et al., 2019), impulsionando o uso de uma grande variedade de frutas no processamento de licores, a exemplos do camu-camu (VIEIRA et al., 2010), açaí (ALVES; MENDONÇA, 2011), limão (REYES-LINARES et al., 2011), maracujá (DIAS et al., 2011), umbu (PEREIRA et al., 2012), abacaxi (PINTO et al., 2017), maçã (STADNIK et al., 2015), tangerina (SILVA et al., 2017), amora preta (LUNA-RAMÍREZ et al., 2017), graviola (OLIVEIRA et al., 2019), goiaba (ALMEIDA; GHERARDI, 2018), manga (SANTOS et al., 2018), jabuticaba (ALMEIDA; GHERARDI, 2019), uva (COELHO et al., 2019) entre outras, entretanto, são escassos trabalhos de processamento de licores de romã.

Considerando-se a necessidade de consumidores que anseiam por novidades no setor de bebidas e estudos que explorem o potencial tecnológico da fruta romã. Objetivou-se a elaboração de um licor à base de romã e canela, bem como a avaliação de sua qualidade físico-química e microbiológica. 


\section{Material e Métodos}

\section{Material}

Os materiais utilizados para a produção do licor foram a fruta romã, vodka com teor alcoólico de 37,5\% (v/v), canela, açúcar refinado e água potável, todos obtidos em supermercados da região metropolitana de Belém-Pará. O experimento foi realizado no Laboratório de Engenharia Química da Universidade Federal do Pará (UFPa).

\section{Elaboração do licor}

O processamento do licor consistiu das etapas de infusão, maceração, filtração, preparo e adição do xarope, envelhecimento (maturação e tranchage), clarificação, envase e armazenamento (Figura 1). Inicialmente, a fruta romã e a canela foram selecionadas, lavadas em água potável, sanitizadas por imersão em solução de cloro (50 ppm/20 minutos), com posterior enxágue e descascamento manual da romã. Em seguida, realizada a infusão por imersão da canela em pau (5\%) e da polpa e semente de romã (95\%) na solução alcoólica (Vodka) para que ocorresse o processo de maceração por um período de 12 dias à temperatura ambiente $\left(25^{\circ} \mathrm{C}\right)$, com subsequente filtração em filtros de nylon. Para o preparo do xarope, houve a adição do açúcar refinado $(400 \mathrm{~g})$ em água potável $(200 \mathrm{~mL})$ e submetidos ao cozimento até atingir concentração de $65^{\circ}$ Brix, com posterior adição do xarope à temperatura ambiente $\left(28^{\circ} \mathrm{C}\right)$ ao licor macerado e filtrado. Durante o envelhecimento, houve a maturação do licor por 32 dias, onde foi realizado o processo de tranchage a cada oito dias para acelerar o processo de envelhecimento do licor. Por fim, o licor elaborado foi submetido a clarificação pelo método de colagem (adição de $10 \mathrm{~g}$ de gelatina para cada litro de licor), seguido de envase em frascos de vidro âmbar e armazenamento à temperatura ambiente $\left(25^{\circ} \mathrm{C}\right)$.

Figura 1. Fluxograma do processamento do licor de romã e canela.

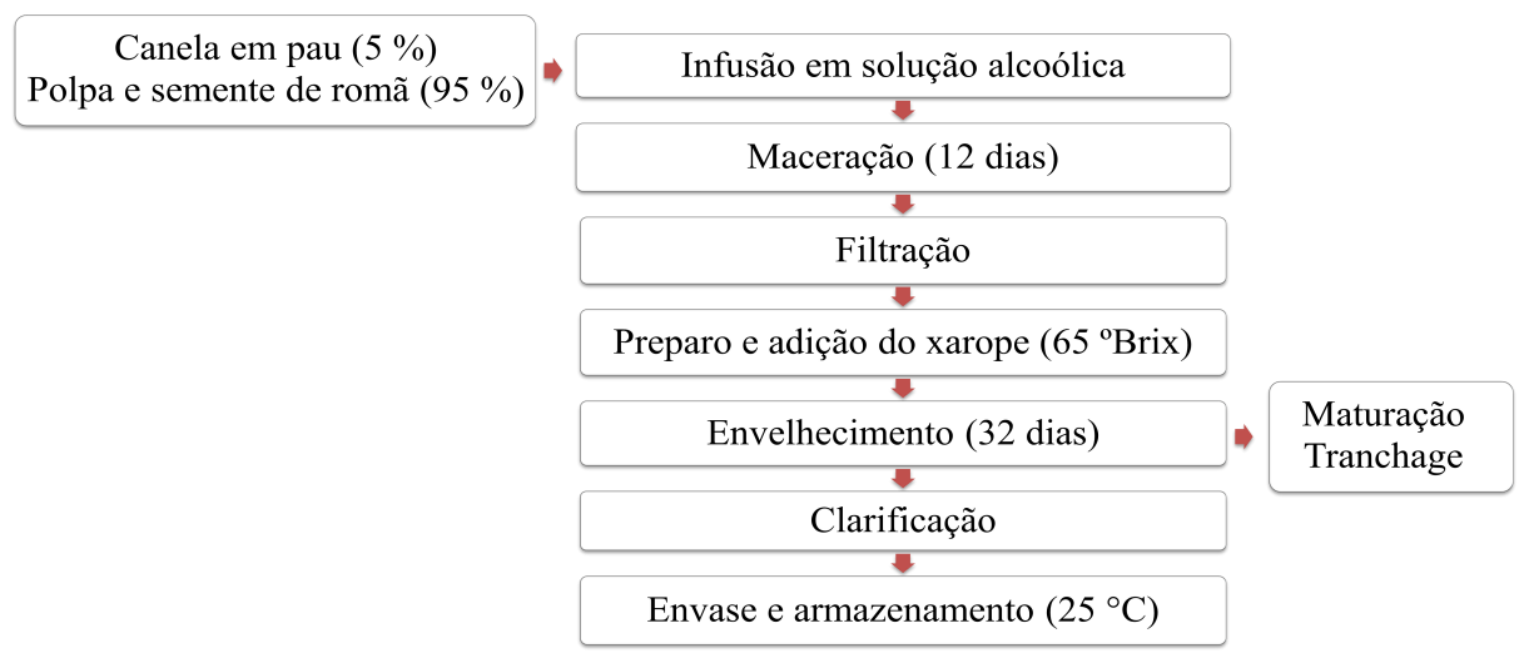

Fonte: Própria (2020). 


\section{Composição físico-química do licor}

Para a determinação da composição centesimal do licor foram utilizadas as metodologias recomendadas pela Association of Official Analytical Chemists (2005): pH em potenciômetro (Marconi- MA 522, São Paulo, Brazil) (método $\mathrm{n}^{\circ}$ 981.12); acidez total titulável (método $\mathrm{n}^{\circ}$ 942.15A); densidade relativa pelo método de deslocamento de fluido em picnômetro (método $\mathrm{n}^{\circ}$ 985.19); cinzas por calcinação em mufla a $550{ }^{\circ} \mathrm{C}$ (método $\mathrm{n}^{\circ}$ 940.26); Extrato seco (método $n^{\circ}$ 940.26); açúcares totais, redutores e não redutores pelo método de Lane-Eynon (método $\mathrm{n}^{\circ}$ 920.183b). Adicionalmente, foram realizadas as análises de sólidos solúveis totais, por leitura direta em refratômetro de bancada (Quimis Q767BD, Diadema, São Paulo, Brazil); O teor alcoólico realizado de acordo com as normas analíticas do Instituto Adolfo Lutz (2008); e compostos fenólicos totais segundo a metodologia proposta por Singleton e Rossi (1965), em espectrofotômetro (SHIMADZU modelo UV 1203, Japão) no comprimento de onda de $750 \mathrm{~nm}$. Para os cálculos de fenólicos totais, foi utilizada uma curva padrão de ácido gálico (20 a 100 mg/L), os resultados foram expressos em mg de ácido gálico (GAE)/100 g.

\section{Avaliação microbiológica}

O licor foi submetido às analises microbiológicas quanto à presença de Salmonella spp., bolores, leveduras, coliformes totais e termotolerante, segundo os métodos descritos pela American Public Health Association (2001).

Para a análise de Salmonella spp, o pré-enriquecimento ocorreu com a homogeneização de $25 \mathrm{~mL}$ da amostra em $225 \mathrm{~mL}$ de água peptonada tamponada $0,1 \%$, incubada a $35^{\circ} \mathrm{C} / 24$ horas. No enriquecimento seletivo, transferiu-se $1 \mathrm{~mL}$ da amostra do préenriquecimento para tubo contentdo $10 \mathrm{~mL}$ de Caldo Selenito Cistina (incubado à $37{ }^{\circ} \mathrm{C} / 24$ horas), $1 \mathrm{~mL}$ para $10 \mathrm{~mL}$ do caldo tetrationato e $1 \mathrm{~mL}$ para $10 \mathrm{~mL}$ do caldo Rappaport Vassiliadis soja (incubados à $43^{\circ} \mathrm{C} / 24$ horas). Para o plaqueamento diferencial foi semeada uma alçada de cada meio do caldo de enriquecimento seletivo para placas ágar Salmonellashigella (SS) e ágar xilose lisina desoxicolato (XLD) e incubadas em placas em posição invertida a $35^{\circ} \mathrm{C} / 24$ horas. Para a confirmação bioquímica, as colônias típicas em ágar foram confirmadas em ágar tríplice açúcar ferro (TSI) e em ágar lisina ferro (LIA) com o auxílio de uma agulha de inoculação por picada e estrias na rampa. Os tubos foram incubados em estufa de $35^{\circ} \mathrm{C} / 24$ horas e então foram avaliadas a utilização dos açúcares e $\mathrm{H}_{2} \mathrm{~S}$ pelas cepas.

A contagem dos coliformes totais e termotolerantes foi determinada pelo método do número mais provável (NMP). $25 \mathrm{~mL}$ da amostra foi homogeneizada em $225 \mathrm{~mL}$ de solução 
salina peptonada $0,1 \%$ e feitas as diluições seriadas para inoculação. O teste presuntivo foi realizado com a inoculação de alíquotas da amostra em três séries de três tubos, contendo tubos de Durhan e caldo lauril sulfato triptose (LST), sendo incubados em estufa a $35^{\circ} \mathrm{C} / 24$ 48 horas. Para confirmação da presença de coliformes, alíquotas de tubos de LST com crescimento microbiano e produção de gás foram transferidas para tubos de caldo verde brilhante $2 \%$ (VB) e caldo Escherichia coli (EC). Para os coliformes totais, os tubos de VB foram incubados à $35^{\circ} \mathrm{C} / 24$ horas, enquanto para os coliformes termotolerantes, os tubos de EC foram incubados à $45^{\circ} \mathrm{C} / 48$ horas.

Para a contagem de Bolores e Leveduras, homogeneizou-se $25 \mathrm{~mL}$ da amostra em 225 $\mathrm{ml}$ de água peptonada alcalina (diluição $10^{-1}$ ) e feitas as diluições sucessivas (diluição $10^{-2} \mathrm{e}$ diluição $10^{-3}$ ). Para o plaqueamento, foi feita a homogeneização e transferência de $1 \mathrm{~mL}$ de cada diluição para as placas de Petri esterilizadas, sendo adicionado $15 \mathrm{~mL}$ de Agar batata dextrose acidificado com ácido tartárico a $10 \%$ e então homogeneizado com movimentos circulares em forma de um oito. Por fim, deixou-se solidificar o Agar e feita a incubação das placas em posição invertida a $22-25^{\circ} \mathrm{C} / 5$ dias.

\section{Resultados e Discussão}

\section{Composição físico-química}

Os resultados das análises físico-químicas do licor de romã e canela estão na Tabela 1.

Tabela 1. Composição físico-química do licor de romã e canela

\begin{tabular}{lc}
\hline Composição & Valores (Média \pm Desvio Padrão) \\
\hline $\mathrm{pH}$ & $4,50 \pm 0,02$ \\
Acidez (meq/L) & $16,67 \pm 2,49$ \\
Densidade $(\mathrm{g} / \mathrm{mL})$ & $1,093 \pm 0,01$ \\
Teor Alcoólico (\% v/v) & $24,00 \pm 0,10$ \\
Cinzas $(\%)$ & $0,033 \pm 0,01$ \\
Extrato Seco (\% g/mL) & $27,94 \pm 0,81$ \\
Sólidos Solúveis Totais $\left({ }^{\circ}\right.$ Brix) & $30,40 \pm 0,10$ \\
Açúcares Totais $(\%)$ & $50,20 \pm 4,19$ \\
Açúcares Redutores $(\%)$ & $13,13 \pm 0,27$ \\
Açucares não Redutor $(\%)$ & $35,21 \pm 4,24$ \\
Compostos Fenólicos Totais (mg GAE/L) & $1041 \pm 0,00$ \\
\hline
\end{tabular}

Fonte: Própria (2020). 
SÁ, C.C.; POMBO, J.C. e BOTELHO, V.A.

O licor apresentou valor de $\mathrm{pH}(4,5)$ próximo aos valores da fruta romã (pH 3,0 a 4,0) mencionados por Moreira et al. (2015). Tal valor se encontra próximo aos resultados de Teixeira et al. (2012), Passos et al. (2013), Almeida e Gherardi (2018), Santos et al. (2018) e Almeida e Gherardi (2019) para os licores de abacaxi (pH 4,40 e 4,46), cenoura com laranja ( $\mathrm{pH} 4,43)$, goiaba ( $\mathrm{pH} 4,15)$, uva ( $\mathrm{pH} 4,20$ ), manga ( $\mathrm{pH} 4,51)$ e jabuticaba ( $\mathrm{pH} 4,08$ e 4,19), respectivamente. Enquanto, Viera et al. (2010), Oliveira e Santos (2011), Dias et al. (2011) e Pereira et al. (2012) observaram valores inferiores na elaboração dos licores de camu-camu (pH 3,60), açaí (pH 3,52), maracujá amarelo (pH 3,57) e umbu (pH 3,58), respectivamente. Já Silva et al. (2017) relataram valores superiores para licores de casca de tangerina (pH 6,04 e 6,35). A variação observada é atribuída as diferentes características e concentrações das frutas utilizadas na elaboração dos licores, além das diferentes condições durante o processo de maceração e envelhecimento.

Segundo Teixeira et al. (2010), com o passar do tempo de maceração os ácidos orgânicos da matéria-prima são extraídos provocando o abaixamento do $\mathrm{pH}$ até atingir o equilíbrio, esse tempo de extração durante a maceração varia de acordo com as matériasprimas utilizadas (frutas e soluções alcoólicas). Simões et al. (2014), mencionam a influência das diferentes fontes alcoólicas no tempo de extração durante a maceração, os autores verificaram que o tempo de estabilização do $\mathrm{pH}$ do extrato foi maior quando foi utilizada a fonte alcoólica a $96,5^{\circ} \mathrm{GL}$ do que a $40^{\circ} \mathrm{GL}$. Oliveira et al. (2015), observaram que os licores de graviola processados com a maior concentração de polpa revelaram os menores valores de $\mathrm{pH}$ devido à maior proporção de polpa/álcool nas formulações ao final da maceração. LunaRamírez et al. (2017), relataram o aumento do $\mathrm{pH}$ do licor de amora preta ( $\mathrm{pH} 4,05$ a 4,28) durante o processo de envelhecimento por 180 dias. Franco e Landgraf (2005) relataram que baixos valores de $\mathrm{pH}$ são importantes, uma vez que, este fator limita o crescimento de bactérias patogênicas e deteriorantes, além de aumentar a vida útil do produto.

A acidez do licor $(16,67 \mathrm{meq} / \mathrm{L})$ está entre os valores dos licores mistos de cenoura com laranja e maracujá (12,0 e 27,8 meq/L) obtidos por Passos et al. (2013). De acordo com Silva et al. (2017), o baixo valor de ácidos encontrado na casca de tangerina $(0,15 \%$ ácido cítrico) contribuiu para as baixas concentrações de acidez dos licores das cascas de tangerina (0,16 a 0,20 \% ácido cítrico). Moreira et al. (2015), mencionam a baixa acidez da fruta romã (0,6 a 0,8 \% ácido cítrico), o que contribui para baixa acidez do licor. Segundo Ataíde et al. (2018), a romã além de ácido cítrico, apresenta ácidos orgânicos que incluem ácido málico, acético, fumárico, tartárico e láctico. As diferentes metodologias de extração dos componentes aromáticos das matérias-primas devido aos diferentes período de infusão 
SÁ, C.C.; POMBO, J.C. e BOTELHO, V.A.

durante a etapa de maceração das bebidas estão relacionadas com o arraste de ácidos orgânicos para a solução alcoólica (OLIVEIRA et al., 2015), bem como o tempo de envelhecimento do licor. Luna-Ramírez et al. (2017), observaram a redução da acidez do licor de amora preta $(0,2048$ a 0,0896 g ácido cítrico/100 mL) durante os 180 dias de envelhecimento. Segundo Almeida et al. (2012), quanto menor a presença de ácidos em licores de frutas mais agradável e melhor será o produto ao paladar dos provadores.

O licor apresentou densidade relativa $(1,0939 \mathrm{~g} / \mathrm{mL})$ entre os valores do licor de amora preta $(1,0709$ a 1,1692 $\mathrm{g} / \mathrm{mL})$ observados por Luna-Ramírez et al. (2017) e próximos aos valores do licor da casca de tangerina $(1,13 \mathrm{~g} / \mathrm{mL})$ mencionado por Viana et al. (2011), licor de açaí $(1,1225 \mathrm{~g} / \mathrm{mL})$ relatado por Oliveira e Santos (2011) e licores de uva e manga $(1,0565$ e 1,0924 g/mL) obtidos por Santos et al. (2018). Luna-Ramírez et al. (2017), relaciona o aumento da densidade do licor com o aumento dos sólidos solúveis na solução hidroalcoólica durante o processo de envelhecimento, por isso é importante a clarificação do licor no final do processo. Segundo Santos et al. (2018), a densidade relativa dos licores é de fundamental importância uma vez que pode evidenciar um possível excesso de borra deixada pela filtração do licor, sendo importante o processo de clarificação da bebida para remover quaisquer partículas em suspensão que possam conferir ao produto uma turvação indesejada e até mesmo a formação de depósito no fundo do frasco de acondicionamento do produto acabado.

O teor alcoólico do licor ( $24 \%$ v/v) está em conformidade com a legislação brasileira, que preconiza variação de 15 a 54 \% (v/v) de álcool para licores de frutas (BRASIL, 2009). Dias et al. (2011) e Santos et al. (2018) reportaram teores alcoólicos próximos aos observados neste estudo em licor de maracujá amarelo (21\% v/v) e licor de manga e uva (24,9 e 25,6 \% v/v), respectivamente. Enquanto, Passos et al. (2013), Oliveira et al. (2016), Pinto et al. (2017), Almeida e Gherardi (2018) e Almeida e Gherardi (2019) encontraram valores inferiores em licores mistos de cenoura com laranja e com maracujá (18\% v/v), graviola $(15,03$ a $16,69 \%$ v/v), abacaxi $(18,93$ a $19,57 \%$ v/v), goiaba $(15 \%$ v/v) e jabuticaba $(14,33$ e 14,37 \%), respectivamente. Já Silva et al. (2017) relataram, em licores de casca de tangerina, valores superiores $(25,57$ e 30,80 \% v/v). De acordo com Luna-Ramírez et al. (2017), o processo de envelhecimento contribui para a redução do teor alcoólico de licores, em seu estudo com licor de amora preta houve a redução do teor alcoólico (58 a 17 \% v/v) durante os 180 dias de envelhecimento, o que pode explicar as variações encontradas em pesquisas com licores. Porém, segundo Simões et al. (2014), a maioria dos licores industriais de frutas possui um teor alcoólico, declarado em rótulo, entre 18 e $25 \%$ em volume, sendo que o mais comum é que haja preferência por aqueles cujo teor alcoólico seja inferior a $25 \%$ em volume. Assim, 
o teor alcoólico é um parâmetro importante na avaliação da aceitabilidade das bebidas alcoólicas, pois à medida que aumenta o teor alcoólico, ocorre uma diminuição na aceitabilidade do produto (BARROS et al., 2008).

O teor de cinzas $(0,03 \%)$ foi semelhante ao valor obtido por Oliveira e Santos (2011), para o licor de açaí $(0,05 \%)$. Segundo Santos et al. (2010), a fruta romã possui baixo teor de cinzas $(0,46 \%)$, o que permiti pressupor que houve baixa migração dos componentes minerais da semente para o álcool durante o processo de maceração, bem como pode ocorrido a perda por volatilização ou pela interação entre os constituintes da amostra.

O extrato seco do licor $(27,94 \%)$ está na faixa dos valores do licores de graviola $(27,56$ a 36,48 \%) observado por Oliveira et al. (2016) e o licor de uva e manga $(24,29$ e $39,63 \%$ ) encontrado por Santos et al. (2018). De acordo com Oliveira et al. (2016), existe uma relação entre o extrato seco e os sólidos solúveis totais presentes no xarope, os autores observaram que os licores de graviola formulados com xarope na concentração de $70{ }^{\circ}$ Brix apresentaram maiores extratos secos (36,48 e 33,40\%), quando comparados aos xaropes na concentração de $50{ }^{\circ}$ Brix $(27,56$ e 28,02 \%), indicando à interferência da sacarose, uma vez que, a sacarose que atua como um sólido se dissolve em maior proporção no xarope, o que afeta a quantidade de sólidos no extrato seco obtidos após a evaporação do álcool. Este fato é confirmado por Santos et al. (2018), que observou durante seu experimento que ao evaporar toda a parte líquida das amostras, restou somente um melado viscoso, relacionado a quantidade do açúcar adicionado ao licor, bem como da quantidade de açúcar da própria fruta adicionado ao mesmo, o que fez com que as amostras não secassem totalmente.

O licor apresentou teores de sólidos solúveis totais (SST) de 30,40 ${ }^{\circ}$ Brix próximo aos valores do licor de camu-camu (33 ${ }^{\circ}$ Brix) encontrado por Viera et al. (2010) e entre os valores do licor de abacaxi $\left(27,4\right.$ a $31^{\circ}$ Brix) observado por Teixeira et al. (2012) e licores mistos de cenoura com laranja e com maracujá (30 e $31{ }^{\circ}$ Brix) obtidos por Passos et al. (2013). Enquanto, Oliveira e Santos (2011), Teixeira et al. (2011), Pereira et al. (2012) e Santos et al. (2018) encontraram valores superiores em licores de açaí (38,6 ${ }^{\circ}$ Brix), maracujá amarelo (48 ${ }^{\circ}$ Brix), umbu (47 ${ }^{\circ}$ Brix) e manga $\left(39^{\circ}\right.$ Brix $)$, respectivamente. Já Almeida et al. (2012), Almeida e Gherardi (2018) e Almeida e Gherardi (2019) relataram valores inferiores em licores de casca de tangerina (23,25 a 23,83 ${ }^{\circ}$ Brix), goiaba (19 ${ }^{\circ}$ Brix) e jabuticaba $(24$ e 27 ${ }^{\circ}$ Brix), respectivamente. Segundo Oliveira et al. (2015), é comum a variação de SST nessas bebidas devido a concentração dos xaropes utilizados com o objetivo de aumentar os açúcares dos licores. Este fato ocorre porque a legislação permite extensa faixa de utilização de açúcar em licores de frutas, preconizando valores superiores a $30 \mathrm{~g} / \mathrm{L}$ (BRASIL, 2009). Outro fator 
SÁ, C.C.; POMBO, J.C. e BOTELHO, V.A.

que contribui com teor de SST do licor é a adição de frutas devido a extração dos açúcares da fruta durante o processo de maceração. Santos et al. (2010), relataram elevado teor de SST na fruta romã (12,89 ${ }^{\circ}$ Brix). Luna-Ramírez et al. (2017), mencionam a influência do tempo do processo de envelhecimento na concentração dos SST, pois observaram o aumento dos SST (30 a $32{ }^{\circ}$ Brix) no licor de amora preta durante os 180 dias de seu envelhecimento. De acordo com Santos et al. (2018), maiores concentração de SST com a evolução da maturação é devido aos processos de biossíntese ou ainda pela degradação de polissacarídeos; esse parâmetro representa uma das melhores formas de avaliar o grau de doçura do produto e a eficácia da clarificação do licor, uma vez que, altos teores de SST significa que a bebida não foi devidamente clarificada.

O licor apresentou valores elevados de açúcares totais (50,20\%), açúcares redutores $(13,13 \%)$ e açúcares não redutores $(35,21 \%)$. O valor dos açúcares totais foi superior aos valores relatados na literatura por Dias et al. (2011), Oliveira e Santos (2011), Pereira et al. (2012) e Silva et al. (2017) para os licores de maracujá amarelo (26,42 \%), açaí (40,50 \%), umbu (45\%) e cascas de tangerina (28,36 e 34,99\%), respectivamente. Enquanto o valor dos açúcares redutores está entre aos resultados obtidos por Dias et al. (2011) e Pereira et al. (2012) em licores de maracujá amarelo (12\%) e umbu (18,46\%), respectivamente. Já o resultado para açúcares não redutores se encontra de acordo com o especificado pela legislação brasileira que estabelece teor igual ou superior a $30 \%$ para licor, o mesmo foi observado por Oliveira e Santos (2011) em licor de açaí (31,76 \%). O licor foi denominado de seco, conforme relatado na legislação, o licor seco é a bebida que contém mais de trinta gramas por litro e no máximo cem gramas por litro de açúcares (BRASIL, 2009). Oliveira et al. (2016), observaram que os licores de graviola formulados com xarope na concentração de $70{ }^{\circ}$ Brix apresentaram maiores teores de açúcares totais (17,61 e 17,97\%), quando comparados aos xaropes na concentração de $60{ }^{\circ}$ Brix $\left(15,47\right.$ a 15,56) e $50{ }^{\circ}$ Brix $(12,63$ e $12,79 \%$ ), demonstrando que a concentração de açúcar utilizado no xarope fará toda diferença nesse parâmetro. Segundo Barros et al. (2008), a combinação adequada de açúcar e teor alcoólico desempenha papel fundamental na aceitação dos licores.

O licor demonstrou ser boa fonte de compostos fenólicos totais (1041 mg GAE/L) com valor superior aos valores encontrados por Pinto et al. (2017) e Santos et al. (2018) em licores de abacaxi (290 a $400 \mathrm{mg}$ GAE/L), uva (83,129 mg GAE/L) e manga (14,518 mg GAE/L), respectivamente. Segundo Carmo et al. (2016), a fruta romã apresenta elevados teores de compostos fenólicos (6,815 e 8,123 mg GAE/g). Pinto et al. (2017) observaram que os compostos fenólicos totais aumentaram com o aumento da concentração de frutas na 
SÁ, C.C.; POMBO, J.C. e BOTELHO, V.A.

bebida alcoólica durante a maceração. Além da quantidade de frutas, o solvente de maceração (fonte extratora) e o processo de amadurecimento (envelhecimento) irão influenciar na quantidade desses compostos (NASCIMENTO et al., 2010). Segundo Simões et al. (2014), a fonte extratora com graduação alcoólica de $96,5^{\circ} \mathrm{GL}$ mostrou-se mais efetiva na extração dos pigmentos do fruto (absorbância) quando comparada a bebida com $40^{\circ} \mathrm{GL}$. Luna-Ramírez et al. (2017) reportaram o aumento dos compostos fenólicos de 43.70 a 50.85 (mg GAE/mL) durante o processo de envelhecimento do licor de amora preta por 180 dias. Os compostos fenólicos são componentes desejáveis em alimentos e bebidas devido sua capacidade antioxidante e benefícios funcionais e nutracêuticos.

$\mathrm{Na}$ Tabela 2, são expressos os resultados das análises microbiológicas (Salmonella spp., coliformes, bolores e leveduras), comparados aos padrões exigidos pela legislação vigente afim de atestar a qualidade sanitária do produto.

Tabela 2. Resultados das análises microbiológicas do licor de romã e canela.

\begin{tabular}{lcc}
\hline Microorganismos & Contagem & *Parâmetro \\
\hline Salmonella spp. & Ausente & Ausente em 25 g \\
Coliformes Totais & $<3 \mathrm{NMP} / \mathrm{mL}$ & - \\
Coliformes Termotolerantes & $<3 \mathrm{NMP} / \mathrm{mL}$ & Máx. 10 NMP/g \\
Bolores e Leveduras & $<15 \mathrm{UFC} / \mathrm{mL}$ & - \\
\hline
\end{tabular}

Fonte: Própria (2020) e *BRASIL (2001).

Os resultados da contagem de Salmonella spp., coliformes, bolores e leveduras, situam-se dentro dos parâmetros propostos pela legislação vigente (BRASIL, 2001). Os estudos de Oliveira e Santos (2011) e Melo Neto et al. (2013), referentes aos licores de açaí e cacau também apresentaram ausência de Salmonella spp., coliformes, bolores e levedura, o que confirma o licor como uma bebida com ótima qualidade microbiológica. Além do teor alcoólico da bebida e da adição das matérias-primas terem contribuido para atividade antimicrobiana da mesma. Segundo Sousa et al. (2018), os compostos bioativos presentes na romã revelam ação antimicrobiana contra diferentes espécies bacterianas, com eficácia maior na inibição de bactérias Gram-positivas quando comparadas as Gram-negativas. Gomes et al. (2018), afirmam que a canela apresenta potencial fungicida e bactericida. Tais resultados garantem a conservação do produto, prolongando sua vida útil. Portanto, o licor elaborado apresentou qualidade microbiológica satisfatória, indicando também que a bebida foi submetida a condições higiênico-sanitárias adequadas durante seu processamento, garantindo o atendimento aos requisitos mínimos de qualidade para o consumo humano. 
SÁ, C.C.; POMBO, J.C. e BOTELHO, V.A.

\section{Conclusão}

O licor de romã e canela foi classificado como licor seco. A bebida produzida apresentou boas características físico-químicas devido aos valores de satisfatórios de $\mathrm{pH}$, acidez, densidade, cinzas, extrato seco, açúcares totais, açúcares redutores e açucares não redutor, bem como teor alcoólico e sólidos solúveis totais dentro dos parâmetros exigidos pela legislação, além de altas concentrações de compostos fenólicos totais, quando comparados com os relatados na literatura. Em relação às análises microbiológicas, a ausência de Salmonella spp. e contagem de coliformes, bolores e leveduras de acordo com o exigido pela legislação brasileira, indica as boas condições higiênico-sanitárias durante a fabricação da bebida, o que confirma sua qualidade. Desta forma, o licor desenvolvido apresenta potencial de comercialização, sendo viável sua produção, por tratar-se de uma tecnologia simples de fácil armazenagem e extensa vida de prateleira, constituindo uma alternativa econômica para o aproveitamento da fruta e geração de renda a pequenos produtores.

\section{Referências}

ALMEIDA, E. L.; LIMA, L. C.; BORGES, V. T. N.; MARTINS, R. N.; BATALINI, C. Elaboração de licor de casca de tangerina. Alimentos e Nutrição, v. 23, n. 2, p. 259-265, 2012.

ALMEIDA, J. C.; ALMEIDA, P. P.; GHERARDI, S. R. M. Potencial uso dos frutos da aceroleira (Malpighiae marginata) para produção de licores. Multi-Science Journal, v. 2, n. 1, p. 7-11, 2019.

ALMEIDA, J. C.; GHERARDI, S. R. M. Elaboração, caracterização físico-química e aceitabilidade de licor de goiaba. Multi-Science Journal, v. 1, n. 13, p. 390-393, 2018.

ALMEIDA, J. C.; GHERARDI, S. R. M. Elaboração, caracterização físico-química e aceitabilidade de licor de jabuticaba. Revista de Engenharias da Faculdade Salesiana, n. 10, p. 20-24, 2019.

ALVES, Y. F. M.; MENDONÇA, X. M. F. D. Elaboração e caracterização sensorial e funcional de um licor típico amazônico a base de açaí (Euterpe oleracea). Revista Brasileira de Tecnologia Agroindustrial, v. 5, n. 2, p. 559-572, 2011. Doi:10.3895/S198136862011000200008

AMERICAN PUBLIC HEALTH ASSOCIATION (APHA). Compendium of Methods for the Microbiological Examination of Foods. $4^{a}$ ed. Washington: APHA, 2001. p. 600.

ASSOCIATION OF OFFICIAL ANALYTICAL CHEMISTS (AOAC). Official Methods of Analysis of the AOAC. $18^{\text {th }}$ ed. Gaithersburg, M.D, USA, 2005.

ATAÍDE, E. M.; SILVA, M. S.; BASTOS, D. C.; SOUZA, J. M. A. Qualidade pós-colheita de romã comercializada no semiárido pernambucano. Agrarian Academy, v. 5, n. 9; p. 429- 
436, 2018. Doi:10.18677/Agrarian_Academy_2018a42

BARROS, J. C.; SANTOS, P. A.; ISEPON, J. S.; SILVA, J. W.; SILVA, M. A. P. Obtenção e avaliação de licor de leite a partir de diferentes fontes alcoólicas. Global Science and Technology, v. 1, n. 4, p. 27-33, 2008.

BRASIL. Agência Nacional de Vigilância Sanitária - Anvisa. Regulamento Técnico sobre padrões microbiológicos para alimentos. Resolução-RDC $\mathrm{n}^{\circ} 12$, de 02/01/01, Diário Oficial da União. Brasília, DF, 10 de jan. 2001. Seção 1.

BRASIL. Ministério da Agricultura, Pecuária e Abastecimento. Decreto $\mathrm{n}^{\circ}$ 6.871, de 4 de Julho de 2009. Dispõe sobre a padronização, a classificação, o registro, a inspeção, a produção e a fiscalização de bebidas. Diário Oficial [da] Republica Federativa do Brasil. Brasília, DF, 05 de jun. 2009.

CARMO, M. C. L.; AlCÂNTARA, B. K.; ALENCAR, S. M.; BEZERRA, R. M. N. Influência das técnicas de cultivo na atividade antioxidante de romã. Multi-Science Journal, v. 1, n. 4, p. 3-6, 2016.

CARRIJO, K. F.; PRAXEDES, C. I. S.; NOBRE, F. S. D.; FRASÃO, B. S.; DUARTE, M. T.; CUNHA, F. L. Condimentos e especiarias empregados no processamento de alimentos: considerações a respeito de seu controle físico-químico. PUBVET, v. 6, n. 26, p. 1-27, 2012.

COELHO, B. E. S.; NÉZIO, E. P. X.; ARAÚJO, A. A.; COELHO, C. L.; SOUSA, K. S. M.; BRAGA, A. C. D. Desenvolvimento e avaliação sensorial do licor de uva Cv. Isabel. Nucleus, v. 16, n. 2, p. 379-387, 2019. Doi:10.3738/1982.2278.3648

DIAS, S. C., CARDOSO, R. L., BATISTA, D. V. S., SANTOS, D. B., ASIS, S. S. Caracterização físico-química e sensorial do licor de corte do maracujá amarelo. Enciclopédia Biosfera, v. 7, n. 13, p. 1405-1412, 2011.

FRANCO, B. D. G.M.; LANDGRAF, M. Microbiologia dos alimentos. 1 ed. São Paulo: SP, 2005. $196 \mathrm{p}$.

GOMES, E. M. C.; FIRMINO, A. V.; PENA, R. C. M.; ALMEIDA, S. S. M. S. Efeito inibitório in vitro de extratos de Cinnamomum zeylanicum blume no controle de Cylindrocladium candelabrum. Ciência Florestal, v. 28, n. 4, p. 1559-1567, 2018. Doi: $10.5902 / 1980509835103$

INSTITUTO ADOLFO LUTZ. Métodos físico-químicos para análise de alimentos. $4^{\mathrm{a}}$ ed., $1^{\mathrm{a}}$ ed. digital. São Paulo: IAL, 2008. 1020 p.

LINGUANOTTO NETO, N.; FREIRE, R.; LACERDA, I. Misturando sabores: receitas e harmonização de ervas e especiarias. São Paulo: Senac, 2016. 160 p.

LUNA-RAMÍREZ， K. Y.; ARELLANO-CÁRDENAS， S.; GARCÍA-PINILLA， S.; CORNEJO-MAZÓN, M. Kinetic analysis of the stability of antioxidants in blackberry (Rubus fruticosus L.) liquor. Revista Mexicana de Ingeniería Química, v. 16, n. 1, p. 121-130, 2017. 
MELO NETO, B. A.; CARVAlHO, E. A.; MELlO D. L. N.; ANJOS A. C.; FERREIRA A. C. R.; SACRAMENTO C. K. Classificação de amêndoas e qualidade de liquor de cacau (Theobroma cacao L.) superior bahia. Revista Brasileira de Produtos Agroindustriais, v. 15, n. 4, p. 391-396, 2013. Doi:10.15871/1517-8595/rbpa.v15n4p391-396

MOREIRA, I. S.; ROCHA, R. H. C.; PAIVA, E. P.; SILVA, H. S.; SOUSA, F. A. Biometria e componentes físico-químicos de romã armazenada sob refrigeração. Pesquisa Agropecuária Tropical (Agricultural Research in the Tropics), v. 45, n. 2, p. 209-215, 2015. Doi:10.1590/1983-40632015v4532501

NASCIMENTO JÚNIOR, B. J.; SANTOS, A. M. T.; SOUZA, A. T.; SANTOS, E. O.; XAVIER, M. R.; MENDES, R. L.; AMORIM, E. L. C. Estudo da ação da romã (Punica granatum $\mathrm{L}$.) na cicatrização de úlceras induzidas por queimadura em dorso de língua de ratos Wistar (Rattus norvegicus). Revista Brasileira de Plantas Medicinais, v. 18, n. 2, p. 423432, 2016. Doi:10.1590/1983-084X/15_125

NASCIMENTO, N. T.; FRUTUOSO, A. E.; MORAES, K. F.; SOARES, D. L.; SILVA, E. D. L.; FARIAS, M. D. Elaboração de um licor funcional a base de Acerola (Malpighia emarginata) com Abacaxi (Ananas comosus). In: Congresso de pesquisa e inovação da rede norte e nordeste de educação tecnológica, 2010, Maceió-AL. Anais do Congresso de pesquisa e inovação da rede norte e nordeste de educação tecnológica, 2010.

OLIVEIRA, E. N. A.; SANTOS, D. C.; GOMES, J. P. ROCHA, A. P. T.; ALBUQUERQUE, E. M. B. Estabilidade física e química de licores de graviola durante o armazenamento em condições ambientais. Revista Brasileira de Engenharia Agrícola e Ambiental, v.19, n.3, p.245-251, 2015. Doi:10.1590/1807-1929/agriambi.v19n3p245-251

OLIVEIRA, E. N. A.; SANTOS, D. C. Processamento e avaliação da qualidade de licor de açaí (Euterpe oleracea Mart.). Revista do Instituto Adolfo Lutz, v. 70, p. 534-41, 2011.

OLIVEIRA, E. N. A.; SANTOS, D. C.; SANTOS, Y. M. G.; BUCHWEITZ, P. R.; GOMES, J. P. Soursop liquor processing: influence of the process variables on the physical and chemical characteristics. Revista Caatinga, v. 29, n. 1, p. 246-256, 2016. Doi:10.1590/198321252016v29n129rc

OLIVEIRA, E. N. A.; SANTOS, D. C.; SANTOS, Y. M. G.; OliVEIRA, F. A. A. Aproveitamento agroindustrial da graviola (Annona muricata L.) para produção de licores: avaliação sensorial. Journal of Biotechnology and Biodiversity, v.7, n.2, p. 281-290, 2019. Doi:10.20873/jbb.uft.cemaf.v7n2.alvesoliveira

OLIVEIRA, L. P.; PINHEIRO, R. C.; VIEIRA, M. S.; PAULA, J. R.; BARA, M. T. F.; VALADARES, M. C. Atividade citotóxica e antiangiogênica de Punica granatum L., Punicaceae. Revista Brasileira de Farmacognosia, v. 20, n. 2, p. 201-207, 2010.

PASSOS, F. R.; CRUZ, R. G.; SANTOS, M. V.; FERNANDES, R. V. B.Avaliação físicoquímica e sensorial de licores mistos de cenoura com laranja e com maracujá. Revista Brasileira de Produtos Agroindustriais, v. 15, n. 3, p. 211-218, 2013.

PEREIRA, K. S.; LEITE, D. S.; SANTOS, P. L. S.; CARDOSO, R. L. Preparo, caracterização físico-química e aceitabilidade de Licor de corte de Spondias tuberosa. 
SÁ, C.C.; POMBO, J.C. e BOTELHO, V.A.

Enciclopédia Biosfera, v.8, n.15, p. 1337-1344, 2012.

PINTO, V. Z.; RODRIGUES, V. N.; SANTOS, D. F.; SANTOS, G. H. F.; BITENCOURT, T. B. Market research, elaboration and characterization of pineapple liqueur. Revista Produção e Desenvolvimento, v.3, n.3, p. 34-42, 2017.

REYES-LINARES, A.; PINO-ALEA, J.; MOREIRA-OCANTO, V. Aspectos generales sobre la elaboración del licor de limón. ICIDCA, v. 45, n. 1, p. 13-19, 2011.

SANTOS, E. H. B.; BATISTA, F. P. R.; PEREIRA, L. M.; CAMPOS, L. M. A.; CASTRO, M. S.; AZEVÊDO, L. C. Composição físico-química dos frutos de romã (Punica granatum L.). In: Congresso de pesquisa e inovação da rede norte e nordeste de educação tecnológica, 2010, Maceió-AL. Anais do Congresso de pesquisa e inovação da rede norte e nordeste de educação tecnológica, 2010.

SANTOS, K. M.; MACHADO, M. A.; GOMES, P. O. M. Caracterização físico-química, determinação de minerais e avaliação do potencial antioxidante de licores produzidos artesanalmente. Multi-Science Journal, v. 1, n. 12, p. 54-61, 2018.

SILVA, R. C.; AMORIM, A. B. F.; FEITOSA, R. M.; OLIVEIRA, E. N. A.; FEITOSA, B. F.; AMADEU, L. T. S. Licor fino de casca de tangerina: processamento e caracterização. Arquivos Brasileiros de Alimentação, v.2, n. 3, p. 164-173, 2017.

SIMÕES, L. S.; TEIXEIRA, L. J. Q.; SARAIVA, S. H.; JUNQUEIRA, M. S. ESTUDO DA Extração dos componentes do abacaxi em função do teor alcoólico e do tamanho da partícula para a produção de licor de abacaxi. Revista Brasileira de Produtos Agroindustriais, v. 16, n. 3, p. 239-246, 2014. Doi:10.15871/1517-8595/rbpa.v16n3p239-246

SOUSA, N. C. F.; GONZAGA, L. F.; RODRIGUES, J. F. S.; FERNANDES, E. S. Propriedades farmacológicas de Punica granatum L (romã): uma revisão de literatura. Revista Ceuma Perspectivas, v. 31, n. 1, p. 57-67, 2018. Doi:10.24863/rccp.v31i1.181

STADNIK, P.; BORGES, S.; BORGES, D. Avaliação da qualidade de licor de maçã com hortelã (Mentha s. p.) elaborado com açúcar orgânico em substituição ao açúcar convencional. Revista Connection Line, n. 12, p. 77-83, 2015.

TEIXEIRA, L. J. Q.; SIMÕES, L. S.; SARAIVA, S. H.; JUNQUEIRA, M. S.; SARTORI, M. A. Determinação da proporção de açúcar e fruta necessários para conferir os atributos ideais ao licor de abacaxi. Enciclopédia Biosfera, v. 8, n. 14, p. 1883-1889, 2012.

TEIXEIRA, L. J. Q.; ROCHA, C. T.; JUNQUEIRA, M. S.; CARNEIRO, J. C. S.; SARAIVA, S. H. Determinação da cinética de extração alcoólica no processamento de licor de café. Enciclopédia Biosfera, v. 6, n. 9, p. 1-9. 2010.

TEIXEIRA, L. J. Q.; ROCHA, C. T.; JUNQUEIRA, M. S.; CARNEIRO, J. C. S.; SARAIVA, S. H. Comparação da cinética de extração em licores de café utilizando diferentes fontes alcoólicas: álcool de cereais e cachaça. Enciclopédia Biosfera, v. 7, n. 12, p.1-15, 2011.

VIANA, L. F.; MUNHOZ, C. L.; SOUZA, A. R. M.; SANTANA, L. M.; MACIEL, V.; CALIARI, M. Development and characterization of the tangerine peel liquor with different 
SÁ, C.C.; POMBO, J.C. e BOTELHO, V.A.

alcoholic bases. Acta Scientiarum. Technology, v. 33, n. 1, p. 95-100, 2011. Doi: 10.4025/actascitechnol.v33i1.7873

VIERA, V. B.; RODRIGUES, J. B.; BRASIL, C. C. B.; ROSA, C. S. Produção, caracterização e aceitabilidade de licor de camu-camu (Myrciaria dúbia (H.B.K.) McVaugh). Alimentação e Nutrição, v. 21, n. 4, p. 519-522, 2010. 